Jurnal Matematika UNAND

Vol. VIII No. 1 Hal. 255 - 259

Edisi Mei 2019

ISSN : 2303-291X

(C)Jurusan Matematika FMIPA UNAND

\title{
SEMIDIRECT PRODUCTS
}

\author{
PUTRI MAY WINDY, I MADE ARNAWA, YANITA \\ Program Studi S1 Matematika, \\ Fakultas Matematika dan Ilmu Pengetahuan Alam, Universitas Andalas, \\ Kampus UNAND Limau Manis Padang, Indonesia. \\ email : putrimaywin@gmail.com
}

Diterima 9 Maret 2019 Direvisi 7 April 2019 Dipublikasikan 7 Mei 2019

\begin{abstract}
Abstrak. Misalkan $G$ adalah grup perkalian, dan $X$ adalah grup Abelian terhadap operasi penjumlahan. Misalkan $\mu: G \rightarrow A u t(X)$ adalah homomorfisma grup. Semidirect products dari $X$ dan $G$ relatif ke $\mu$ didefinisikan sebagai $X \rtimes_{\mu} G=\{(x, a) \mid x \in X, a \in G\}$, dengan operasi $\left(x_{1}, a_{1}\right)\left(x_{2}, a_{2}\right)=\left(x_{1}+\mu\left(a_{1}\right)\left[x_{2}\right], a_{1} a_{2}\right)$, untuk $x_{1}, x_{2} \in X$ dan $a_{1}, a_{2} \in G$. Tulisan ini membahas bagaimana hubungan semidirect products dengan homomorfisma grup dan sifat-sifat semidirect products.

Kata Kunci: Grup, Subgrup, Subgrup Normal, Homomorfisma, Isomorfisma, Semidirect Products
\end{abstract}

\section{Pendahuluan}

Himpunan tak kosong $G$ membentuk sebuah grup jika di $G$ didefinisikan suatu operasi biner "*" sedemikian sehingga himpunan $G$ dengan operasi biner "** memenuhi sifat tertutup dan asosiatif. Kemudian di $G$ terdapat unsur identitas terhadap operasi biner "**, dan setiap unsur di $G$ mempunyai invers.

Semidirect products atau biasa dikenal dengan hasil kali semi langsung merupakan perluasan dari direct products. Ada dua konsep yang berkaitan erat dengan semidirect products yaitu inner semidirect product dan outer semidirect product.

Pada makalah ini dimisalkan $G$ adalah grup terhadap operasi perkalian dan $X$ adalah grup abelian terhadap operasi penjumlahan, dan $\mu$ suatu pemetaan homomorfisma dari $G$ ke $A u t(X)$, maka akan dijelaskan bagaimana hubungan semidirect products dengan homomorfisma grup dan sifat-sifat semidirect products dari $X$ dan $G$ relatif ke $\mu$.

\section{Landasan Teori}

\subsection{Grup Dan Subgrup}

Definisi 2.1. [4] Suatu himpunan tidak kosong $G$ dikatakan suatu grup jika pada $G$ dapat didefinisikan suatu operasi, ditulis "*" sedemikian sehingga :

(1) Untuk setiap $a, b \in G$ berlaku $a * b \in G$ (Sifat Tertutup). 
(2) Untuk setiap $a, b, c \in G$ berlaku $a *(b * c)=(a * b) * c$ (Sifat Asosiatif).

(3) Terdapat suatu unsur di $G$ yang dilambangkan dengan e, sehingga untuk setiap $a \in G$ berlaku $a * e=e * a=a$ (Keberadaan Unsur Identitas).

(4) Untuk setiap $a \in G$, terdapat suatu unsur $a^{-1} \in G$, sehingga berlaku $a * a^{-1}=$ $a^{-1} * a=e$ (Keberadaan Unsur Invers).

Grup $G$ dengan operasi biner "**" dapat ditulis sebagai $(G, *)$. Untuk selanjutnya, dalam tulisan ini $a * b$ ditulis $a b$, untuk setiap $a, b \in G$.

Definisi 2.2. [4] Suatu grup $G$ disebut grup abelian (grup komutatif) jika untuk setiap $a, b \in G$ berlaku $a b=b a$.

Lema 2.3. [4] G adalah grup, maka

(1) Unsur identitas di $G$ adalah tunggal.

(2) Setiap a $\in G$ memiliki invers tunggal di $G$.

(3) Untuk setiap $a \in G,\left(a^{-1}\right)^{-1}=a$.

(4) Untuk semua $a, b \in G,(a \cdot b)^{-1}=b^{-1} \cdot a^{-1}$.

Definisi 2.4. [4] Suatu himpunan bagian tak kosong $H$ dari $G$ dikatakan subgrup dari $G$ jika dengan operasi biner yang sama dengan $G$ maka $H$ juga membentuk grup.

Lema 2.5. [4] Suatu himpunan bagian tak kosong $H$ dari $G$ adalah subgrup dari $G$, jika dan hanya jika :

(1) Untuk setiap $a, b \in H$, berlaku $a b \in H$.

(2) Untuk setiap $a \in H$, berlaku $a^{-1} \in H$.

\subsection{Koset}

Definisi 2.6. [1] Misalkan $H$ subgrup dari $G$, dan $a \in G$ :

$$
H a=\{h a \mid h \in H\}
$$

disebut koset kanan dari $H$ oleh a dan,

$$
a H=\{a h \mid h \in H\}
$$

disebut koset kiri dari $H$ oleh a.

\subsection{Subgrup Normal dan Grup Faktor}

Definisi 2.7. [4] Suatu subgrup $N$ dari $G$ dikatakan subgrup normal dari $G$ jika untuk setiap $g \in G$ dan $n \in N$ berlaku gng $^{-1} \in N$.

Teorema 2.8. [2] Misalkan H subgrup dari grup $G$, maka perkalian koset kiri yaitu dengan persamaan

$$
(a H)(b H)=(a b) H
$$

terdefinisi dengan baik jika dan hanya jika koset kiri dan koset kanan sama, sedemikian sehingga $a H=H a$ untuk semua $a \in G$. 


\subsection{Isomorfisma}

Definisi 2.9. [4] Suatu pemetaan $\phi$ dari grup $G$ ke grup $G^{\prime}\left(\phi: G \rightarrow G^{\prime}\right)$ dikatakan homomorfisma jika untuk semua $a, b \in G$

$$
\phi(a b)=\phi(a) \phi(b) .
$$

Lema 2.10. [4] Misalkan $G$ adalah suatu grup, $N$ adalah subgrup normal dari $G$. Didefinisikan $\phi$ suatu pemetaan dari $G$ ke $G / N$ oleh $\phi(x)=N x$, untuk semua $x \in G$, Maka $\phi$ adalah homomorfisma dari $G$ pada $G / N$.

Definisi 2.11. [4] Jika $\phi$ adalah homomorfisma dari $G$ ke $G^{\prime}$. Kernel $\phi$ didefinisikan dengan $\operatorname{Ker}(\phi)=\left\{x \in G \mid \phi(x)=e^{\prime}, e^{\prime}=\right.$ identitas unsur di $\left.G^{\prime}\right\}$.

Lema 2.12. [4] Jika $\phi$ adalah pemetaan homomorfisma dari $G$ ke $G^{\prime}$ maka:

(1) $\phi(e)=e^{\prime}, e^{\prime}$ suatu unsur identitas dari $G^{\prime}$.

(2) $\phi\left(x^{-1}\right)=\phi(x)^{-1}$, untuk semua $x \in G$.

Definisi 2.13. [4] Suatu pemetaan $f: A \rightarrow B$ dikatakan pemetaan satu-satu jika untuk setiap unsur $x_{1}$ dan $x_{2}$ dipetakan sama oleh $f$, yaitu $f\left(x_{1}\right)=f\left(x_{2}\right)$ berlaku $x_{1}=x_{2}$.

Definisi 2.14. [4] Suatu pemetaan $f: A \rightarrow B$ dikatakan pemetaan pada jika untuk setiap unsur $y \in B$ terdapat unsur $x \in A$ yang memenuhi $f(x)=y$.

Lema 2.15. [4] Jika $\phi$ adalah pemetaan homomorfisma dari $G$ ke $G^{\prime}$ dengan kernel $K$, maka $K$ adalah subgrup normal dari $G$.

Teorema 2.16. [6] Pemetaan $f$ memiliki invers jika dan hanya jika $f$ satu-satu dan pada.

Definisi 2.17. [4] Suatu homomorfisma $\phi$ dari $G$ ke $G^{\prime}$ dikatakan suatu isomorfisma jika $\phi$ satu-satu dan $\phi$ pada .

Definisi 2.18. [4] Dua grup $G, G^{\prime}$ dikatakan isomorfik jika terdapat suatu isomorfisma dari $G$ pada $G^{\prime}$. G yang isomorfik ke $G^{\prime}$ dinotasikan dengan $G \approx G^{\prime}$.

Teorema 2.19. [6] Suatu homomorfisma $f: G \rightarrow G^{\prime}$ adalah satu-satu jika dan hanya jika $\operatorname{Ker}(f)=\{e \mid e \in G\}$.

Teorema 2.20. [4] (Teorema Pertama Isomorfisma) Misalkan $f$ suatu homomorfisma dari $G$ pada $G^{\prime}$ dengan kernel $K_{f}$, maka $G / K_{f} \cong G^{\prime}$.

\section{Pembahasan}

Definisi 3.1. [5] Misalkan $G$ adalah grup dengan subgrup $K$ dan $N$, sehingga

(i) $K$ adalah subgrup normal di $G$.

(ii) $N \cap K=\{\mathrm{e}\}$.

(iii) $N K=G$, dengan $N K=\{n k \mid n \in N, k \in K\}$. 
258 Putri May Windy dkk

Maka $G$ disebut semidirect products dari $K$ dan $N$.

Definisi 3.2. [4] Suatu isomorfisma dari $G$ ke $G$ sendiri disebut dengan automorfisma.

Teorema 3.3. [6] Misalkan $G$ suatu grup. Aut $(G)$ merupakan notasi dari himpunan semua automorfisma dari $G$, maka Aut $(G)$ suatu grup terhadap pemetaan komposisi.

Definisi 3.4. [5] Misalkan $G$ adalah grup perkalian, dan $X$ adalah grup Abelian terhadap penjumlahan. Misalkan $\mu: G \rightarrow$ Aut $(X)$ adalah homomorfisma grup. "Semidirect products" dari $X$ dan $G$ relatif ke $\mu$ didefinisikan sebagai

$$
X \rtimes_{\mu} G=\{(x, a) \mid x \in X, a \in G\},
$$

dengan operasi $\left(x_{1}, a_{1}\right)\left(x_{2}, a_{2}\right)=\left(x_{1}+\mu\left(a_{1}\right)\left[x_{2}\right], a_{1} a_{2}\right)$, untuk $x_{1}, x_{2} \in X$ dan $a_{1}, a_{2} \in G$.

Teorema 3.5. [5] Misalkan G suatu grup terhadap operasi perkalian, X suatu grup abelian terhadap operasi penjumlahan dan $\mu: G \rightarrow$ Aut $(X)$ adalah grup homomorfisma, maka

(a) semidirect product $X \rtimes_{\mu}$ G suatu grup.

(b) Himpunan $K=\left\{(x, a) \in X \rtimes_{\mu} G \mid x=0\right\}$ subgrup dari $X \rtimes_{\mu}$ G yang isomorfik ke $G$.

(c) Himpunan $N=\left\{(x, a) \in X \rtimes_{\mu} G \mid a=\right.$ e $\}$ subgrup normal dari $X \rtimes_{\mu}$ G yang isomorfik ke $X$ dan $\left(X \rtimes_{\mu} G\right) / N$ yang isomorfik ke $G$.

\section{Kesimpulan}

Berdasarkan uraian sebelumnya, dapat disimpulkan sebagai berikut:

(1) Misalkan $G$ suatu grup. Aut $(G)$ merupakan notasi dari himpunan semua automorfisma dari $G$, maka $A u t(G)$ suatu grup terhadap pemetaan komposisi.

(2) Semidirect product $X \rtimes_{\mu} G$ suatu grup.

(3) Himpunan $K=\left\{(x, a) \in X \rtimes_{\mu} G \mid x=0\right\}$ subgrup dari $X \rtimes_{\mu} G, K$ isomorfik ke $G$.

(4) Himpunan $N=\left\{(x, a) \in X \rtimes_{\mu} G \mid a=e\right\}$ subgrup normal dari $X \rtimes_{\mu} G$ yang isomorfik ke $X \operatorname{dan}\left(X \rtimes_{\mu} G\right) / N$ yang isomorfik ke $G$.

\section{Ucapan Terima kasih}

Terima kasih kepada Bapak Dr. Admi Nazra, Ibu Nova Noliza Bakar, M.Si dan Bapak Narwen, M.Si selaku penguji sehingga makalah ini dapat diselesaikan dengan baik.

\section{Daftar Pustaka}

[1] Ehrlich, G. 1991. Fundamental Concepts of Abstract Algebra. PWS-KENT Publishing Company, United States of America. 
[2] Fraleigh, J. B and K, Victor. 1994. A First Course In Abstract Algebra, Fifth Edition. Addison-Wesley Publishing Company, United States of America.

[3] Gallian, J. A. 2010. Contemporary Abstract Algebra, Seventh Edition. Brooks/Cole, Cengage Learning, United States of America.

[4] Herstein, I. N. 1975. Topics In Algebra, Second Edition. New York.

[5] Beachy, J. A. 1995. Abstract Algebra, Supplementary Lecture Notes. Northerm Illinois University.

[6] Khanna, V. K and Bhambri, S. K. 1993. A Course In Abstract Algebra, $5^{\text {th }}$ ed. Vikas Publishing House PVT LTD, New Delhi. 